\title{
On the Short-Range Structure of Amorphous Calcium Hydrogen Phosphate
}

Bing-Qiang Lu ${ }^{[\mathrm{a}, \mathrm{b}] *}$, Natalya A. Garcia ${ }^{[\mathrm{c}]}$, Daniel M. Chevrier ${ }^{[\mathrm{d}]}$, Peng Zhang ${ }^{[\mathrm{d}]}$, Paolo Raiteri ${ }^{[\mathrm{c}]}$, Julian D. Gale ${ }^{[\mathrm{c}]}$ and Denis Gebauer $^{[\mathrm{b}, \mathrm{e}] *}$

[a] Dr. B. Q. Lu

State Key Laboratory of High Performance Ceramics and Superfine Microstructure,

Shanghai Institute of Ceramics, Chinese Academy of Sciences

Dingxi Road 1295, Shanghai 200050, P.R. China

Email: b.q.lu@mail.sic.ac.cn

[b] Prof. Dr. D. Gebauer

Department of Chemistry, Physical Chemistry

University of Konstanz

Universitätsstrasse 10, Box 714, D-78457 Konstanz, Germany

[c] N. A. Garcia, A/Prof. P. Raiteri, Prof. J. D. Gale

Curtin Institute for Computation/The Institute for Geoscience Research (TIGeR), School of Molecular and Life Sciences, Curtin University, PO Box U1987, Perth, Western Australia 6845, Australia.

[d] Dr. D.M. Chevrier, Prof. P. Zhang

Department of Chemistry

Dalhousie University

Halifax, NS, B3H4R2, Canada

[e] present address:

Prof. Dr. D. Gebauer

Institute of Inorganic Chemistry

University of Hanover

Callinstr. 9, D-30167 Hanover, Germany

Correspondence: gebauer@acc.uni-hannover.de (D. Gebauer); b.q.lu@mail.sic.ac.cn (B. Q. Lu) 


\begin{abstract}
Calcium orthophosphates (CaPs) are the hard constituents of bones and teeth, and thus of ultimate importance to humankind, while amorphous CaPs (ACPs) may play crucial roles in CaP biomineralization. Among the various ACPs with $\mathrm{Ca} / \mathrm{P}$ atomic ratios between 1.0 1.5, an established structural model exists for basic $\mathrm{ACP}(\mathrm{Ca} / \mathrm{P}=1.5)$, while those of other ACPs remain unclear. Herein, the structure of amorphous calcium hydrogen phosphate ( $\mathrm{ACHP} ; \mathrm{Ca} / \mathrm{P}=1.0$ ) obtained via aqueous routes at near-neutral $\mathrm{pH}$ values, without stabilizers, was studied by experiments (mainly, TEM with ED, XRD, IR and NMR spectroscopies, as well as EXAFS) and computer simulation. Our results globally show that ACHP has a distinct short-range structure, and we propose calcium hydrogen phosphate clusters (CHPCs) as its basic unit. This model is consistent with both computer simulations, and the experimental results, where CHPCs are arranged together with water molecules to build up ACHP. We demonstrate that Posner's clusters, which are conventionally accepted to be the building unit of basic ACPs, do not represent the short-range structure of ACHP, as Posner's clusters and CHPCs are structurally distinct. This finding is important not only for the determination of the structures of diverse ACPs with varying $\mathrm{Ca} / \mathrm{P}$ atomic ratios, but also for fundamental understanding of a major mineral class that is central to biomineralization in vertebrates, and, thus, humans, in particular.
\end{abstract}

\title{
Introduction
}

Calcium orthophosphates $(\mathrm{CaPs})$ constitute a diverse family of minerals that play important roles in both geology and biology. Among them, carbonated hydroxyapatite is vital for humankind, as it is the mineral constituent of bones and teeth. ${ }^{1,2}$ Due to related health issues like osteoporosis, the exploration of the mechanisms of $\mathrm{CaP}$ mineralization brings about the great promise to find solutions to upcoming health issues of our ageing societies, ${ }^{1,3}$ but is also attractive from a fundamental science perspective.

Transient amorphous intermediates generally play important roles in biomineralization processes. This is particularly well established for the case of calcium carbonate, ${ }^{4,5}$ which is the most abundant 
biomineral, and may also involve liquid mineral precursors stabilized by acidic macromolecules. ${ }^{6}$ The role of amorphous calcium (ortho)phosphate (ACP) in biomineralization, however, has been a matter of considerable debate. ${ }^{7-14}$ Today, there is mounting evidence that in animal bones and teeth, ACP is a precursor to apatites (or an important component of the complex structures), ${ }^{15-22}$ and liquid precursors may also play a role in $\mathrm{CaP}$ biomineralization. ${ }^{23-25} \mathrm{HPO}_{4}{ }^{2-}$ ions were shown to be present within an "acidic" ACP, which is thought to be essential for CaP biomineralization. ${ }^{21}$ Generally, the term "acidic" ACP implies that $\mathrm{HPO}_{4}{ }^{2-}$ ions are present in the material, yielding $\mathrm{Ca} / \mathrm{P}$ atomic ratios between $\sim 1.0-1.5$ even though it is obtained at near-neutral, slightly basic $\mathrm{pH}$ values.

Synthetic ACP can transform into octacalcium phosphate (OCP), hydroxyapatite (HAP) or calciumdeficient hydroxyapatite (CDHA) ${ }^{26}$ where the $\mathrm{Ca} / \mathrm{P}$ atomic ratio varies. This implies that the $\mathrm{Ca} / \mathrm{P}$ atomic ratio in amorphous intermediates may be a key factor for controlling the structure of the subsequently formed crystalline CaPs. ${ }^{26}$ Basic $\mathrm{ACP}(\mathrm{Ca} / \mathrm{P}=1.5)$ is built up from so-called Posner's clusters, ${ }^{27}$ i.e., $\mathrm{Ca} 9\left(\mathrm{PO}_{4}\right)_{6}$ units with a diameter of $0.95 \mathrm{~nm}$, which are also a building block of hydroxyapatite when arranged in crystallographic register, together with additional $\mathrm{Ca}^{2+}$ and $\mathrm{OH}^{-}$ions. ${ }^{27,}{ }^{28}$ It has been suggested that deviations from a $\mathrm{Ca} / \mathrm{P}$ ratio of $\sim 1.5$ in ACPs are mostly due to surface adsorbed, more soluble phases arising from non-aqueous syntheses, or the additional incorporation of calcium ions. ${ }^{26}$ This led to the conclusion that Posner's clusters may also generally represent the short-range order in chemically different ACPs. ${ }^{26}$ However, the structure of "acidic" ACPs with lower $\mathrm{Ca} / \mathrm{P}$ atomic ratios, has been less studied. ${ }^{29,30}$ In the investigated examples, the $(\mathrm{Ca} / \mathrm{Mg}) / \mathrm{P}$ atomic ratio was not lower than 1.15 , and the structure of pure amorphous calcium hydrogen phosphate (ACHP; i.e., with an invariant $\mathrm{Ca} / \mathrm{P}$ atomic ratio of 1.0) has not yet been determined, although it was previously prepared in the presence of impurities from aqueous solutions, whereas the $\mathrm{Ca} / \mathrm{P}$ ratio of the obtained precipitates was not experimentally confirmed. ${ }^{31,32}$ Moreover, stabilizers likely affected the structure of the AC(H)Ps, while some structural differences among $\mathrm{AC}(\mathrm{H}) \mathrm{Ps}$ prepared under different conditions were also reported. ${ }^{33,34}$ Indeed, $\mathrm{HPO}_{4}{ }^{2-}$ ions were presumed to be present in pre- and post-nucleation species during $\mathrm{CaP}$ mineralization in tris(hydroxymethyl)methyl aminomethane) (TRIS)-buffered saline solutions at 
physiological conditions ( $\mathrm{pH} 7.4),{ }^{35}$ although the validity of the assumptions made to arrive at the claimed speciation was subsequently challenged. ${ }^{36}$

While organic components and ion substitutions may influence the structure and crystallization behavior of ACPs, studying the pure forms is a fundamental pre-requisite in order to be able to discuss any specific roles that these foreign species may play, for instance, in biomineralization. Furthermore, the determination of the structure of ACHP could be required for investigating those of other ACPs with intermediate $\mathrm{Ca} / \mathrm{P}$ atomic ratios, which could be conceived of as chemical intermediaries between basic ACP and ACHP, of which only the former structure is known until now. Herein, we synthesized ACHP via an aqueous route with a confirmed atomic ratio of $\mathrm{Ca} / \mathrm{P}=\sim 1.0$. Notably, the synthesis was achieved without the use of additional stabilizers that might affect its structural characteristics. We use basic ACP $(\mathrm{Ca} / \mathrm{P}=1.5)$ and crystalline $\mathrm{CaPs}$ with different $\mathrm{Ca} / \mathrm{P}$ ratios as reference materials in detailed structural analyses. This, in conjunction with computer simulations, leads us to propose a structural basic unit for describing this amorphous form of $\mathrm{CaP}$, the calcium hydrogen phosphate cluster (CHPC), which is structurally distinct from Posner's clusters building up basic ACPs.

\section{Results and discussion}

$\mathrm{AC}(\mathrm{H}) \mathrm{Ps}$ with different $\mathrm{Ca} / \mathrm{P}$ atomic ratios were prepared by mixing $\mathrm{CaCl}_{2}$ and $\mathrm{Na}_{3} \mathrm{PO}_{4}$ solutions with different $\mathrm{pH}$ values. ACPs prepared at $\mathrm{pH} 11.9$ and $\mathrm{pH} 8.9$ exhibit $\mathrm{Ca} / \mathrm{P}$ ratios of 1.47 and 1.02 (according to ICP-OES, Supporting Information (SI), Experimental Section, Table S1), and are regarded as basic ACP and ACHP, all respectively. Transmission electron microscopy (TEM) analyses show that the $\mathrm{AC}(\mathrm{H}) \mathrm{Ps}$ consist of particles with sizes in the range of tens to hundreds of nanometers (Figure 1). The selected area electron diffraction (SAED) patterns (insets, Figure 1) do not show distinct reflections, proving the absence of long-range order and confirming their amorphous character. 

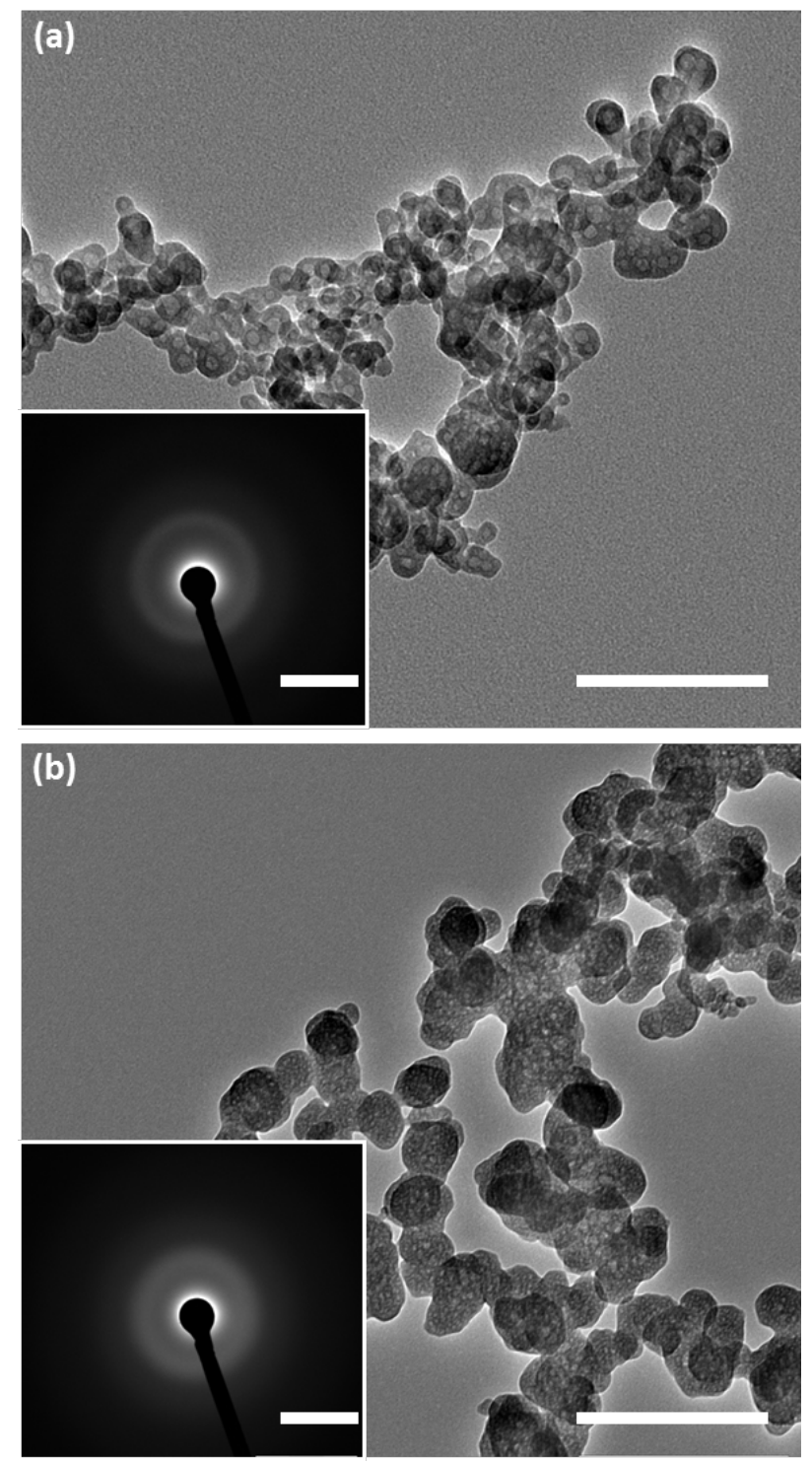

Figure 1. TEM micrographs of basic ACP (a) and ACHP (b). The insets show corresponding SAED patterns. The scale bars are $100 \mathrm{~nm}$ and $0.51 / \AA$ for the micrographs and SAED data, respectively.

The X-Ray powder diffractograms (XRD) show two broad peaks for each ACP (Figure S1), one is relatively strong at around $2 \theta=25-35^{\circ}$, the other one is much weaker at around $2 \theta=40-55^{\circ}$. This indicates that the basic ACP and ACHP do possess distinct short- to medium-range orders, but neither form exhibits crystalline long-range order. Notably, the maximum position of the stronger peak varies slightly in between basic ACP and ACHP, shifting to lower $2 \theta$ values for ACHP by ca. $1^{\circ}$ (Figure $2 \mathrm{a}$ ), already indicating differences in the structural characteristics of basic ACP and ACHP. These were further explored by means of Fourier Transform Infrared Spectroscopy (FTIR) analyses (SI section S1 and Figure 2b). The single $v_{3}$ band $\left(1047 \mathrm{~cm}^{-1}\right)$ in the FTIR spectrum of basic ACP corresponds to the asymmetric 
stretch vibration of $\mathrm{P}-\mathrm{O}\left(\right.$ in $\left.\mathrm{PO}_{4}\right)$, and is split into $v_{6}$, and $v_{6}$, bands in the spectrum of ACHP due to the presence of $\mathrm{HPO}_{4}{ }^{2-}$ ions (Figure S2b). At the same time, the $v_{4}$ bands, corresponding to the O-P-O bending vibration, shift from $567 \mathrm{~cm}^{-1}$ (basic ACP) to $543 \mathrm{~cm}^{-1}$ (ACHP). This indicates that the lengths of the PO bonds, and/or the symmetry of the surrounding short-range orders in ACP and ACHP are indeed different. The $v_{3}$, bands, corresponding to the $\mathrm{P}-\mathrm{OH}\left(\mathrm{HPO}_{4}\right)$ stretching mode, are clearly seen in the spectrum of ACHP, which corroborates that $\mathrm{HPO}_{4}{ }^{2-}$ ions are structural constituents, and confirms the substitution of $\mathrm{PO}_{4}{ }^{3-}$ by $\mathrm{HPO}_{4}{ }^{2-}$ when compared with the spectrum of basic ACP. FTIR spectral differences between dicalcium phosphate dihydrate (DCPD, $\left.\mathrm{CaHPO}_{4} \cdot 2 \mathrm{H}_{2} \mathrm{O}\right)$ and $\mathrm{ACHP}$ also show that the hydrogen bonding of neighboring hydrogen phosphates in ACHP is distinct, whereas structural relations with neither dicalcium phosphate $\left(\mathrm{DCP}, \mathrm{CaHPO}_{4}\right)$ nor octacalcium phosphate $(\mathrm{OCP}$, $\mathrm{Ca}_{8} \mathrm{H}_{2}\left(\mathrm{PO}_{4}\right)_{6} \cdot 5 \mathrm{H}_{2} \mathrm{O}$ ) are evident (SI section S1 and Figure S2, S3). For more detailed discussions of the IR spectra, see the SI, section S1.

Further insight into the structural role of $\mathrm{HPO}_{4}{ }^{2-}$ ions in ACHP was obtained by ${ }^{1} \mathrm{H}$ magic angle spinning (MAS) NMR spectroscopy (SI, Figure S4-S6). The broad resonance of $\mathrm{HPO}_{4}{ }^{2-}$ ions (7-14 ppm) is observed in case of ACHP, but not basic ACP (SI, Figure S4). The broad resonance at $\sim 4$ ppm arises from chemisorbed or structural $\mathrm{H}_{2} \mathrm{O}$, and is seen in the MAS NMR spectra of both amorphous forms (SI, Figure S4). ${ }^{1} \mathrm{H}$ MAS NMR spectra of other crystalline CaPs (SI, Figure S5) are all different from that of ACHP. However, comparison of the ${ }^{1} \mathrm{H}$ MAS NMR spectra of ACHP and DCPD (SI, Figure S6) shows that the respective chemical environments of the protons of $\mathrm{HPO}_{4}{ }^{2-}$ and $\mathrm{H}_{2} \mathrm{O}$ are similar. 

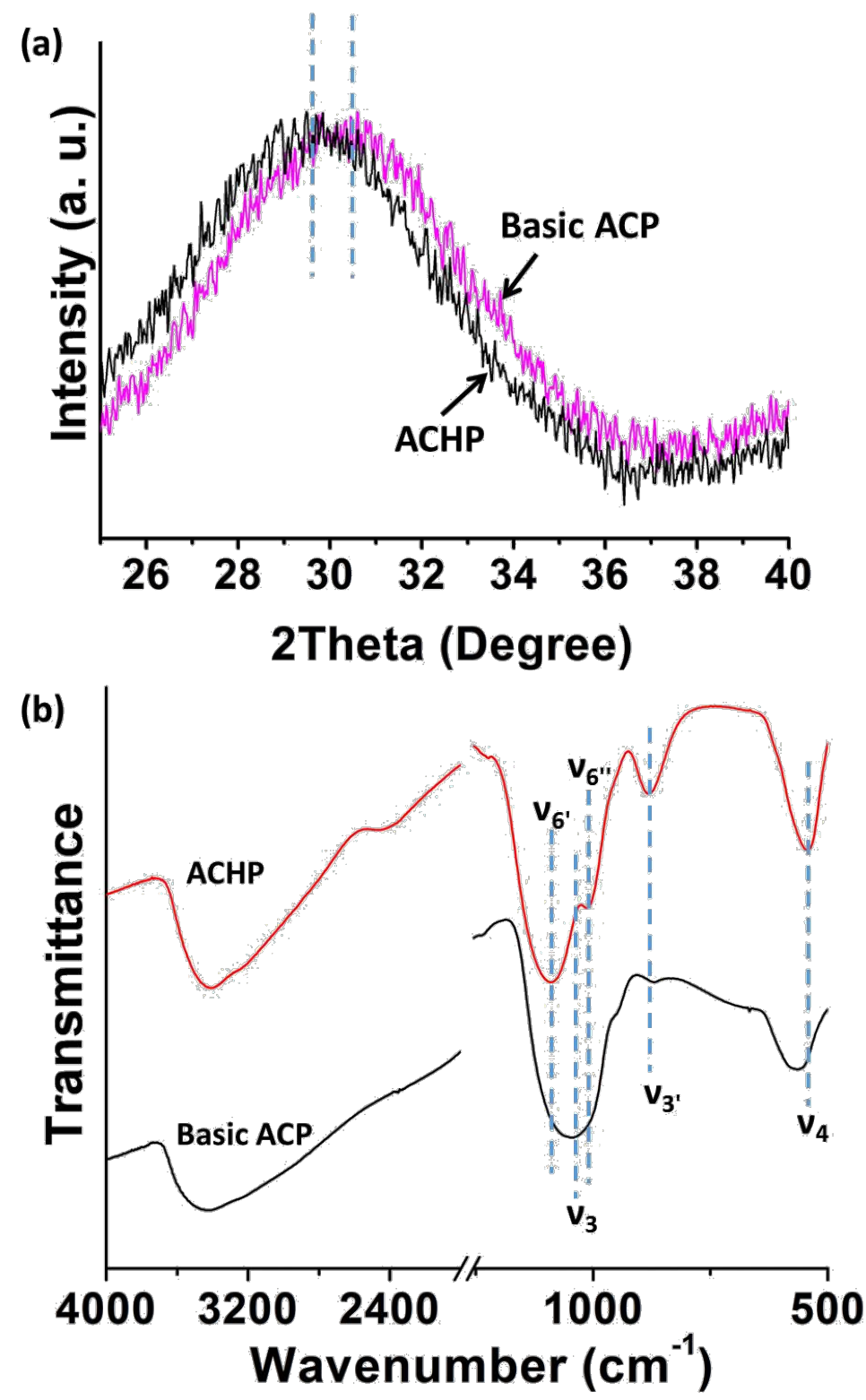

Figure 2. XRD patterns (a) and FTIR spectra of basic ACP and ACHP. The XRD patterns with full $2 \theta$ range corresponding to (a) can be found in the SI, Figure S1. The dashed vertical lines are guides for the eye to illustrate the shift of the peaks. " $v_{\mathrm{i}}$ " represent different vibrational modes $\mathrm{i}$ of the phosphate ion. The band assignments follow Bailey et al. ${ }^{37}$.

${ }^{31}$ P MAS NMR spectra (Figure 3) show that basic ACP and ACHP display single, broad Gaussianshaped resonances in the range of $-15 \sim 15 \mathrm{ppm}$, whereas the maximum position is centered at 0.32 and $2.2 \mathrm{ppm}$ for ACHP and basic ACP, respectively. For crystalline CaPs, only HAP and DCPD exhibit single resonances (SI Figure S7). The peak maximum positions of basic ACP (2.2 ppm) and HAP (1.9 ppm) agree within experimental accuracy (SI, Figure S8), as is the case for ACHP (0.32 ppm) and DCPD (0.40 
ppm) (SI, Figure S9). This indicates that the P chemical environment of ACHP is, on average, similar to that of DCPD, but no other crystalline CaP. This corroborates the notion already suggested by the corresponding ${ }^{1} \mathrm{H}$ MAS NMR spectra.

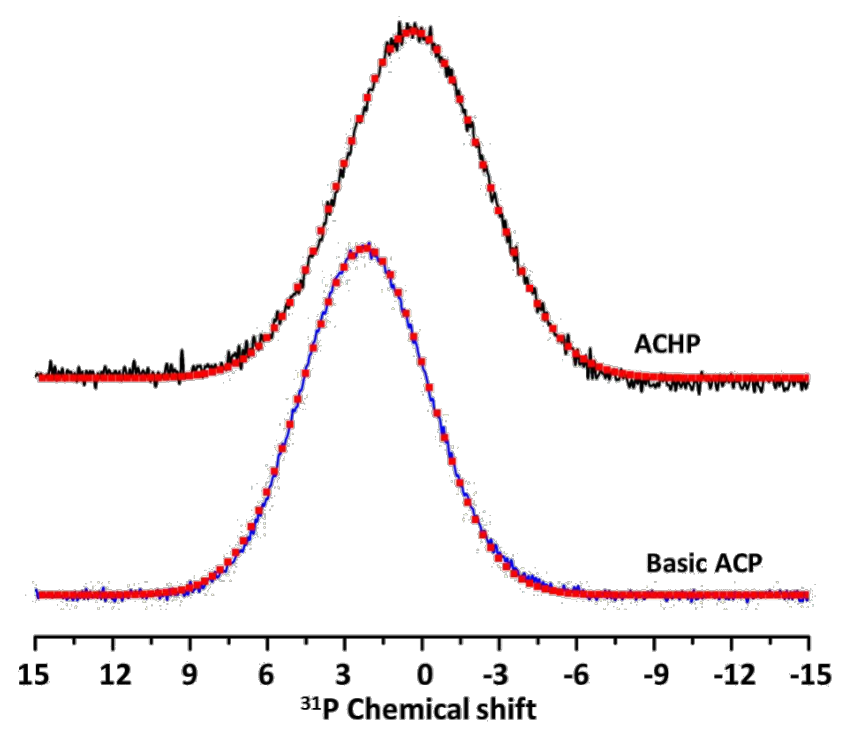

Figure 3. ${ }^{31} \mathrm{P}$ MAS NMR spectra of different ACPs. ${ }^{1} \mathrm{H}$ de-coupling was applied. $\mathrm{NH}_{4} \mathrm{H}_{2} \mathrm{PO}_{4}$ was used as the references (set as $0 \mathrm{ppm}$ ). Solid curves: original spectra; dotted curves: Gaussians from the fitting of the original spectra.

To further shed light on the structural configurations in basic ACP, ACHP and different $\mathrm{CaPs}$, Ca Kedge x-ray absorption near edge structure (XANES) and extended x-ray absorption fine structure (EXAFS) analyses were performed (Figure 4 and SI, Figure S10). The Ca K-edge XANES spectra of DCPD, HAP, basic ACP and ACHP (Figure 4a) show a pre-edge peak between 4037-4041 eV, and a white line (the most intense peak following the absorption edge) in the energy range of 4045-4055 eV. The maxima positions of the pre-edge peaks do not show any significant differences, while their normalized intensities vary (Figure 4b). The intensity of the pre-edge feature is similar for basic ACP and ACHP, and lies in between that of DCPD and HAP. This particular feature relates to $\mathrm{Ca} 1 \mathrm{~s} \rightarrow \mathrm{Ca} 3 \mathrm{~d} / \mathrm{O} 2 \mathrm{p}$ transitions. Thus, the higher pre-edge intensity of HAP could originate from the distinct combination of highly coordinated Ca-O sites. As for the white line features, the two ACPs are essentially identical in regard to both the peak maximum position $(4049.7 \mathrm{eV})$ and the intensity (Figure 4c). The white line position of DCPD (4050.0 $\mathrm{eV}$ ) is close to that of the ACPs, while that of HAP is split into two peaks at 4048.9 and $4051.2 \mathrm{eV}$. The 
split in the spectrum of HAP is due to the presence of two unique crystallographic sites for $\mathrm{Ca}^{38,39} \mathrm{The}^{3}$ relative intensity of this main absorption feature corresponds well with the Ca-O scattering intensity in the EXAFS spectra (i.e., higher white line intensity will result from more Ca-O coordination, see the SI, Figure S11, Table S2, and section S2, for details). These results indicate that the short-range environments of the $\mathrm{Ca}$ atoms in the basic $\mathrm{ACP}$ and $\mathrm{ACHP}$ are very similar in regard to their $\mathrm{Ca}-\mathrm{O}$ local structure $(\mathrm{Ca}-$ $\mathrm{P}$ or $\mathrm{Ca}-\mathrm{Ca}$ are not visible for basic ACP and ACHP due to their amorphous character). The similarity of Ca environments between basic ACP and ACHP is consistent with previous EXAFS measurements, ${ }^{29,30,}$ 40 although the "acidic" ACP studied therein had a $\mathrm{Ca} / \mathrm{P}$ atomic ratio significantly larger than 1 . For "acidic" ACP, by investigating casein-stabilized micelles containing CaP with X-Ray Absorption Spectroscopy, Holt et al. proposed that the $\mathrm{O}$ atoms from $\mathrm{H}_{2} \mathrm{O}$ and $\mathrm{HPO}_{4}{ }^{2-}$ coordinate to the $\mathrm{Ca}$ ion to form the first shell of the short-range order. ${ }^{41}$ However, this is also the case for the Posner's cluster model, where water can contribute to the coordination to $\mathrm{Ca}$ ions, since 8 of $9 \mathrm{Ca}$ ions in a Posner's cluster are located at the surface. 

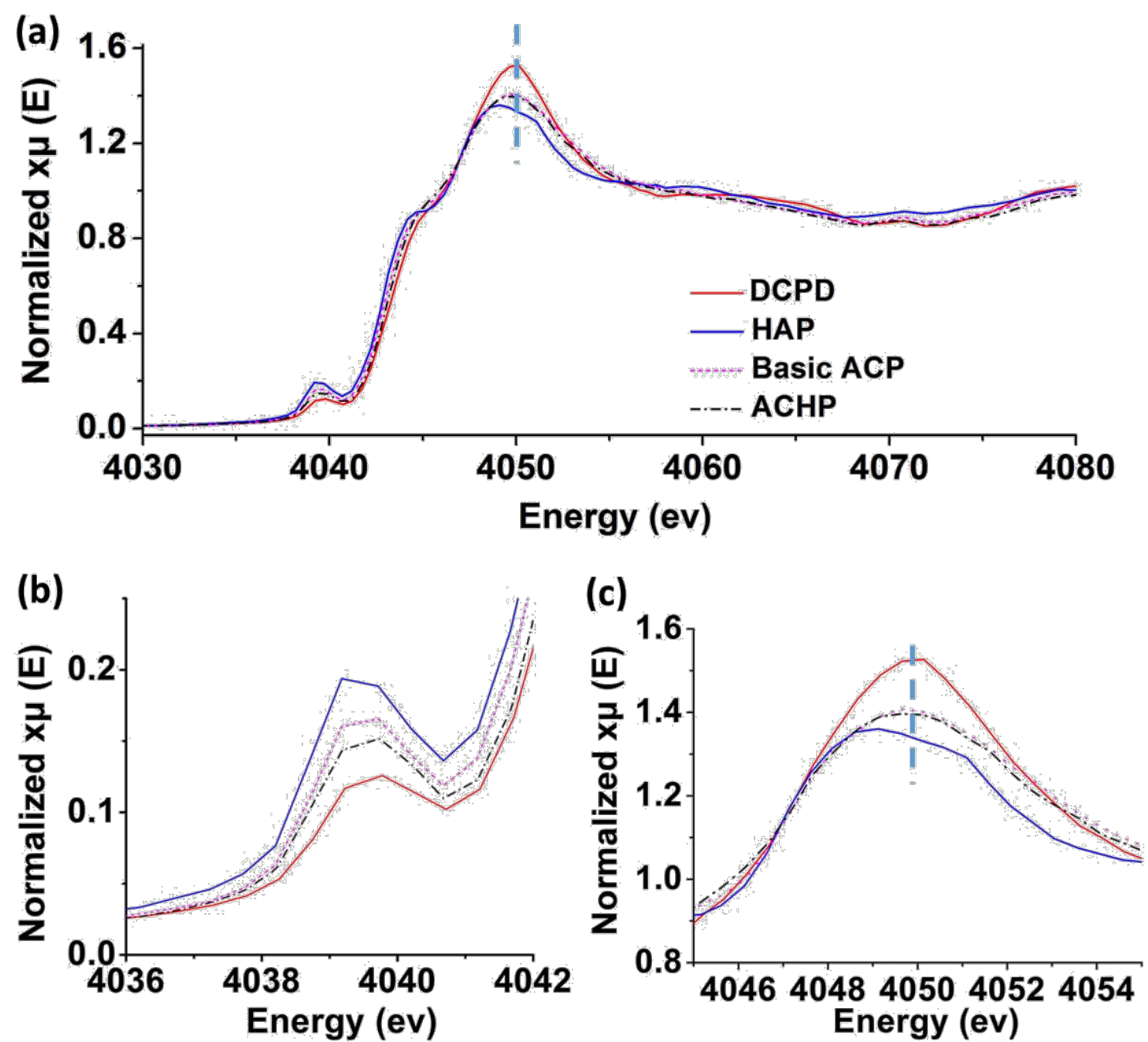

Figure 4. Normalized Ca K-edge XANES (a-c) spectra of DCPD, HAP, basic ACP and ACHP. (b) and

(c) show magnified regions of the spectra in the energy range of the pre-edge, 4036-4042 eV (b) and white line, $4045-4055 \mathrm{eV}$ (c).

In order to investigate the structure of the possible building unit of ACHP, assuming a Ca:P ratio of 1:1, we monitored the stability of various clusters in an aqueous environment using computer simulations (Experimental Section for selection rules and simulation details; SI, Figure S12, S13, Table S3, and section S3 for detailed discussion). The neutral $\left(\mathrm{CaHPO}_{4}\right)_{6}$ cluster (CHPC) was among the most stable of the clusters, remaining together for the full duration of the simulations (20 ns), and exhibited dynamic switching between two main configurations (SI, Figure S13). While $\left[\mathrm{Ca}_{6}\left(\mathrm{HPO}_{4}\right)_{4}\left(\mathrm{PO}_{4}\right)_{2}\right]^{-2}$ and $\left[\mathrm{Ca}_{6}\left(\mathrm{HPO}_{4}\right)_{5}\left(\mathrm{PO}_{4}\right)\right]^{-1}$ clusters were also comparatively stable during the simulation times studied, the aggregation of a negatively charged cluster yielding ACHP is assumed to be less favorable. We note that 
a definitive determination of the free energy landscape of clusters in aqueous solution is beyond the scope of the present work, which deals with the solid-state building unit.

Studying a single CHPC in vacuum, it evolves into a structure shown in the Figure 5a-c. The addition of $6 \mathrm{H}_{2} \mathrm{O}$ molecules coordinating with the CHPC (the $\mathrm{H}_{2} \mathrm{O} / \mathrm{P}$ ratio is 1.0, SI section $\mathrm{S} 4$ ), the structure remains essentially unchanged, though the waters do not distribute evenly across the calcium ions and the structure becomes skewed (Figure 5d). Comparing this CHPC with a Posner's cluster in vacuum (SI, Figure S14), similar to the one proposed by Treboux et $\mathrm{al}^{42}$, the configuration of CHPC differs greatly from that of the Posner's cluster with or without $\mathrm{H}_{2} \mathrm{O}$ coordination (see details in SI, section S3).

(a)

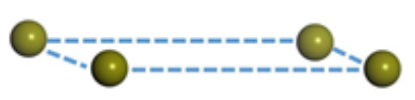

$\odot$

(c)

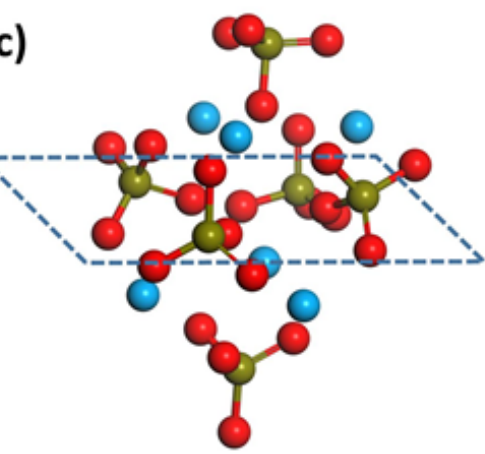

(b)

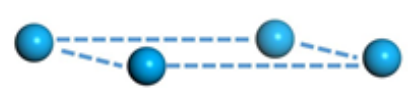

$\odot$

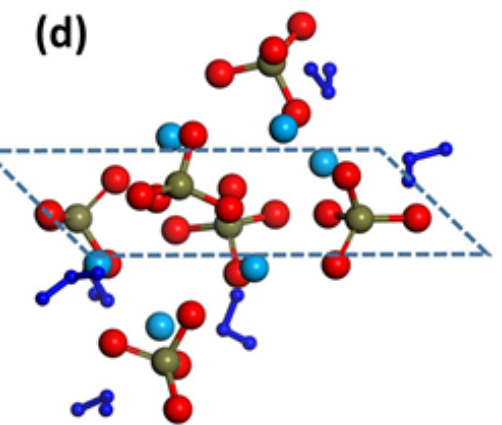

Figure 5. Configurations of $\mathrm{CHPC}$ in vacuum taken from simulation. (a-c) The arrangement of $\mathrm{P}(\mathrm{a}), \mathrm{Ca}$ (b) and all atoms (c). (d) CHPC with $\mathrm{H} 2 \mathrm{O}$ molecules. The dashed quadrangles indicate the (disordered) rectangles formed by $\mathrm{P}$ atoms (a, c, d) and $\mathrm{Ca}$ atoms (b). $\mathrm{Ca}$ is shown in cyan, $\mathrm{P}$ in tan, $\mathrm{O}$ in red; $\mathrm{H}$ of $\mathrm{HPO}_{4}$ is not shown; $\mathrm{H}_{2} \mathrm{O}$ are shown in blue.

A structural model of ACP solid is further obtained by computer simulation (Figure 6). While the studies of cluster stability in water indicate probable structures, assuming the 1:1 Ca:P ratio proposed 
experimentally, it is also useful to compare the properties of an amorphous model built from clusters with this ratio to an amorphous solid built from Posner's clusters, which have a Ca:P ratio of 9:6. Hence amorphous models were created from both species. The densities of the resulting amorphous materials were calculated to be $2.09 \pm 0.03 \mathrm{~g} / \mathrm{cm}^{3}$ for $\mathrm{Ca}_{6}\left(\mathrm{HPO}_{4}\right)_{6}\left(\mathrm{H}_{2} \mathrm{O}\right)_{6}$ and $2.13 \pm 0.03 \mathrm{~g} / \mathrm{cm}^{3}$ for $\mathrm{Ca}_{9}\left(\mathrm{PO}_{4}\right)_{6}\left(\mathrm{H}_{2} \mathrm{O}\right)_{12}(\mathrm{SI}$, Table S4, Figure S16, S17). As expected, these are significantly lower than the experimental values for crystalline phases, such as $\mathrm{Ca}_{5}(\mathrm{OH})\left(\mathrm{PO}_{4}\right)_{3}$ and $\mathrm{CaHPO}_{4}$ which are $3.16^{43}$ and 2.92 $\mathrm{g} / \mathrm{cm}^{3}{ }^{44}$ respectively, due to the presence of stoichiometric amounts of water. The calcium coordination number by water for the amorphous solid built from hydrated Posner's clusters was slightly lower than the solid built from $\mathrm{Ca}_{6}\left(\mathrm{HPO}_{4}\right)_{6}\left(\mathrm{H}_{2} \mathrm{O}\right)_{6}(6.76 \pm 0.03$ vs $7.32 \pm 0.09$, respectively, $(\mathrm{SI}$, Table S4), reflecting the more closed, spherical structure of the Posner's cluster and the larger amount of stoichiometric water. It follows that the phosphate coordination number by calcium for the amorphous solid built from hydrated Posner's cluster was higher than the solid built from $\mathrm{Ca}_{6}\left(\mathrm{HPO}_{4}\right)_{6}\left(\mathrm{H}_{2} \mathrm{O}\right)_{6}(6.02 \pm 0.03$ vs. $4.59 \pm 0.08)$ (SI, Table S4), due to the higher amount of stoichiometric Ca to P. We also note that longer $100 \mathrm{~ns}$ simulations in both cases do not result in significantly different CNs. Using an analysis of the coordination number of individual Ca sites with water oxygen we can identify the packing structure (SI, Table S5). In both basic ACP and ACHP the amount of bound water suggests that the cluster packing includes interstitial water bound to $\mathrm{Ca}$. We expect that the amount of unbound $\mathrm{Ca}$ will be higher in ACHP due to the lower stoichiometric ratio of water but the magnitude of the increase (55\% versus basic ACP's 33\%) suggests that there is a different packing pattern. However, the water oxygen environment indicates that there is more bulk-like water in basic ACP than ACHP (SI, Table S5).

For the plane wave density functional theory (DFT) calculations, it was necessary to construct small unit cells to model the amorphous structures. In the case of the structures based on hydrated Posner's clusters and on a composition of $\mathrm{CaHPO}_{4} \cdot \mathrm{H}_{2} \mathrm{O}$, the unit cells both contained 300 atoms, which correspond to four Posner or five $\left(\mathrm{CaHPO}_{4}\right)_{6}$ clusters plus either 48 or 30 water molecules, respectively. After relaxation at the PBE-D2 level of theory, the densities were 2.19 and $2.22 \mathrm{~g} / \mathrm{cm}^{3}$, also respectively. Both densities are similar to those for the larger force field simulations quoted above. One unexpected feature 
of the amorphous $\mathrm{CaHPO}_{4} \cdot \mathrm{H}_{2} \mathrm{O}$ material was that a proton transfer reaction occurred spontaneously, resulting in a disproportionation of $2 \mathrm{HPO}_{4}{ }^{2-}$ anions into $\mathrm{H}_{2} \mathrm{PO}_{4}{ }^{-}$and $\mathrm{PO}_{4}{ }^{3-}$. Attempts to redistribute the protons to different sites in order to attain the expected composition were unsuccessful, suggesting that the tendency to form a specific protonation state depends on the local environment of the $\mathrm{PO}_{4}$ tetrahedron within the amorphous material. The same behavior was observed for two independently generated models of this amorphous phase.
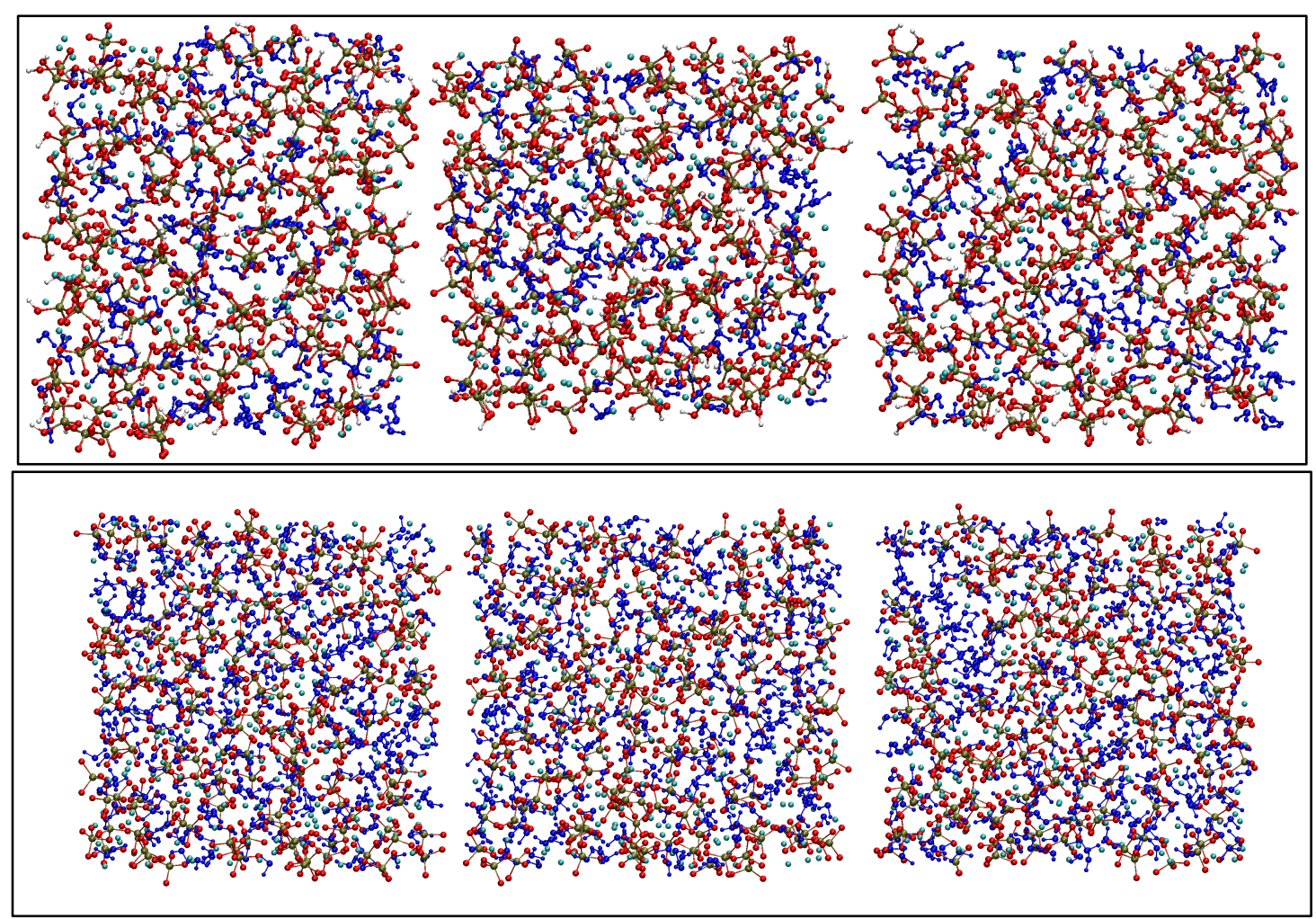

Figure 6. Two amorphous models built from $\mathrm{Ca}_{6}\left(\mathrm{HPO}_{4}\right)_{6}\left(\mathrm{H}_{2} \mathrm{O}\right)_{6}$ clusters (top row) and $\mathrm{Ca}_{9}\left(\mathrm{PO}_{4}\right)_{6}\left(\mathrm{H}_{2} \mathrm{O}\right)_{12}$ clusters (bottom row) shown along each of the three orthogonal axes. Here $\mathrm{Ca}$ is cyan; phosphate $\mathrm{O}$ is red, $\mathrm{H}$ is white and $\mathrm{P}$ is tan; $\mathrm{H}$ and $\mathrm{O}$ of water are shown in blue to highlight the approximately uniform dispersal of water, phosphate ions and calcium ions.

Previous experimental and computational evidence showed that Posner's clusters are the building units of basic ACP, which agrees with our simulations. In the calculated density maps of the clusters within the amorphous solid (Figure 6), the Posner's clusters maintain their geometry over the course of the simulations (Figure 7, left). There is some increased diffusivity as evidenced by the slight smearing of 
the atomic positions but the overall geometry observed in vacuum and in aqueous solution, where a central $\mathrm{Ca}$ is surrounded by $6 \mathrm{PO}_{4}$ and $8 \mathrm{Ca}$ atoms with a cluster diameter of $\sim 9 \AA$, is maintained. However, our simulations of ACHP suggests that the CHPCs, with a larger average diameter $(\sim 10 \AA)$, are more distorted within the solid and in many cases exchange ions and molecules between units, with no single stable cluster geometry (Figure 7, right). Thus, though the existence of CHPC in ACHP is confirmed here, it does not specifically suggest that ACHP is constructed via addition of clusters with a uniform configuration.

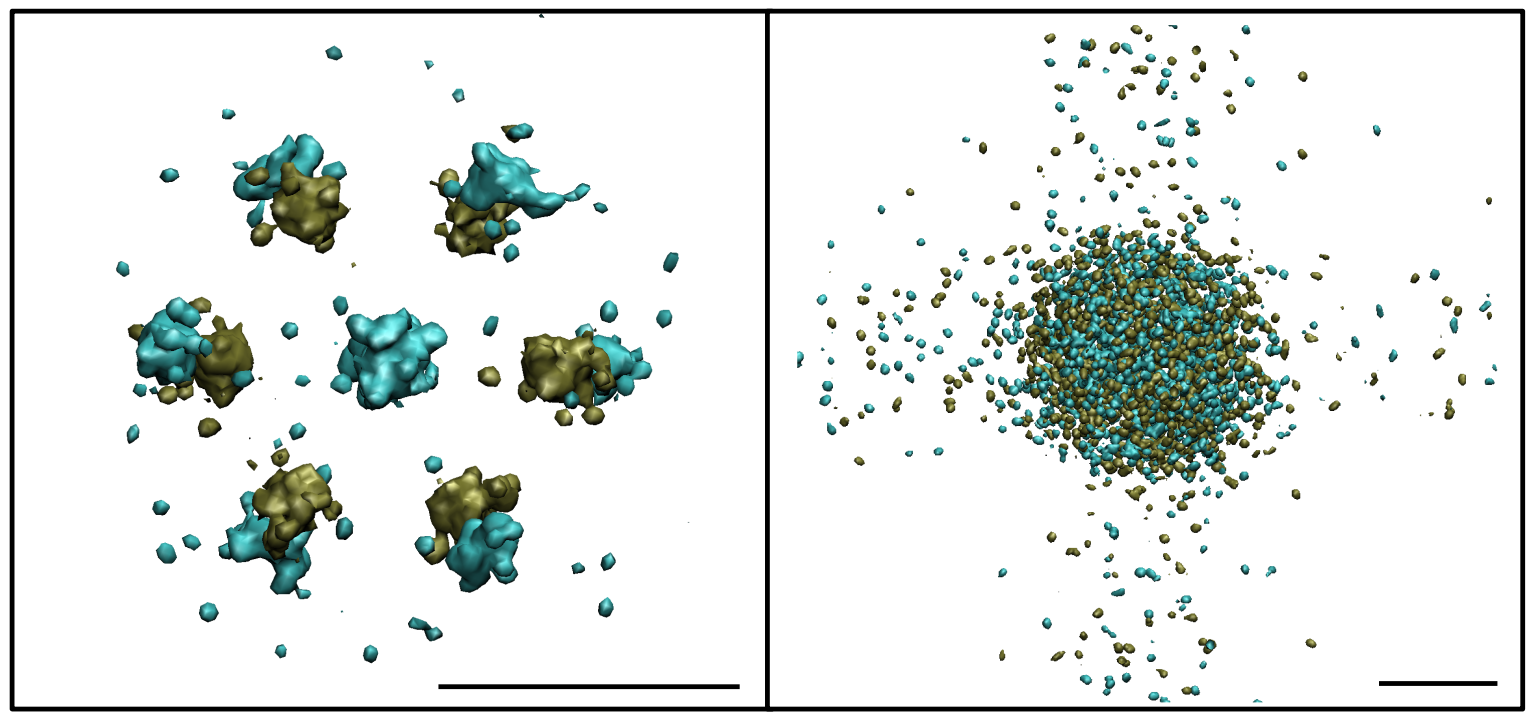

Figure 7. Average 3D atomic density maps of (left) the $\mathrm{Ca} 9\left(\mathrm{PO}_{4}\right)_{6}\left(\mathrm{H}_{2} \mathrm{O}\right)_{6}$ cluster and (right) the $\mathrm{Ca}_{6}\left(\mathrm{HPO}_{4}\right)_{6}\left(\mathrm{H}_{2} \mathrm{O}\right)_{6}$ cluster within the amorphous solid. The iso-density surfaces have been colored based on atom type where phosphorus is tan and calcium is cyan; oxygen and hydrogen have been omitted for clarity. In both cases scale bars are $5 \AA$. Individual clusters were selected from the solid based on their initial geometry and superimposed using a method described in S1.

\section{Conclusions}

In conclusion, our data shows that the structure of ACHP is distinct from basic ACP and cannot be described by Posner's clusters, nor disordered/Ca-deficient Posner's clusters. We thus propose a novel structural model for ACHP (Figures 6-7) based upon simulation. Similar to basic ACPs, we propose that ACHP consists of CHPCs (Figure 7) that are aggregated with $\mathrm{H}_{2} \mathrm{O}$ in the interstices to build up the structure of ACHP. Unlike the Posner's clusters, however, the CHPC has lower symmetry and is more 
susceptible to structural change on formation of an amorphous solid. The chemisorbed, structural $\mathrm{H}_{2} \mathrm{O}$ molecules coordinating to $\mathrm{Ca}$ ions or even exhibiting hydrogen-bonding interactions with the $\mathrm{HPO}_{4}{ }^{2-}$ ions are arranged around the CHPC to build up ACHP. This structure is globally consistent with the experimental analyses as follows:

(1) The Ca environments are similar for basic ACP and ACHP in the short- to medium-range. From the simulations, the $\mathrm{Ca}-\mathrm{O}$ coordination number (first shell) is similar throughout calcium sites in the amorphous solids at $7.32 \pm 0.09$ for ACHP and $6.76 \pm 0.04$ for basic ACP.

(2) The P short-range environments differ between basic ACP and ACHP. In addition to the complete substitution of phosphate ions by hydrogen phosphate ions, the interactions between the $\mathrm{Ca}$ and $\mathrm{HPO}_{4}$ $\left(\mathrm{PO}_{4}\right)$ ions change due to rather distinct $\mathrm{Ca}$ arrangements around $\mathrm{P}$. This is seen in the calculated P-Ca coordination number, which is lower for ACHP than for basic ACP $(4.62 \pm 0.03$ and $6.02 \pm 0.04$, respectively). The different bonding configurations give rise to the distinct FTIR spectral features observed experimentally.

(3) The chemical environment of the P atoms in ACHP and DCPD is similar according to ${ }^{31}$ P MAS NMR spectra, which is due to identical $\mathrm{Ca} / \mathrm{P}$ atomic ratios within homogeneous phases.

(4) Comparison of the computed (SI, Figure S15) and experimental (SI, Figure S4) proton NMR spectra reveals that the calculated spectrum supports the assignment of the broad feature at high chemical shifts to clusters of $\mathrm{CaHPO}_{4}$ in $\mathrm{ACHP}$, and that the experimental data is inconsistent with an amorphous solid composed of Posner-like clusters (for further discussions, see SI, section S5).

(5) $\mathrm{HPO}_{4}{ }^{2-}$ ions transform into $\mathrm{P}_{2} \mathrm{O}_{7}{ }^{4-}$ ions in the second step of TGA measurements (SI, Figures S18-21, and section S4), as opposed to DCPD. Because the CHPCs are not connected within a long-range order crystallographic arrangement, and nearly all the $\mathrm{HPO}_{4}{ }^{2-}$ ions are at the surface of the clusters close to water molecules within the structure of ACHP, the $\mathrm{HPO}_{4}{ }^{2-}$ ions are less stable than in DCPD upon heating.

All of this reveals that ACHP is structurally distinct from all other known CaPs, and its short-range environment can be described by means of CHPCs. This suggests that at least ACHP cannot be seen as a proto-crystalline form ${ }^{4,45,46}$ that directly relates to a certain crystalline $\mathrm{CaP}$, although its $\mathrm{Ca} / \mathrm{P}$ atomic ratio 
agrees with that of DCPD. As the structures of both basic ACP and ACHP are now established, it should be investigated whether or not other ACPs with varying $\mathrm{Ca} / \mathrm{P}$ atomic ratios $(1<\mathrm{Ca} / \mathrm{P}<1.5)$ are intermediaries of the two forms, from a structural point of view. In addition, these pure forms also provide the fundamental point of reference for investigating specific roles that organic components and ion substitutions might play, for instance, in biomineralization. Certainly, ACHP can serve as an amorphous intermediate for the formation of different crystalline forms of CaP (SI, Figures S22, S23), and its crystallization behavior will have to be studied in detail, in the future. Last, but not least, we note that the current solid-state characterization and structural model must not be extrapolated to the solution state, where pre-nucleation clusters occur, which have very likely a different structure and speciation than the CHPC building units of $\mathrm{AC}(\mathrm{H}) \mathrm{P}^{36}$.

\section{Experimental Section}

\section{Preparation of $\mathrm{AC}(\mathrm{H}) \mathrm{Ps}$}

$1.67 \mathrm{mmol} \mathrm{CaCl} 2 \cdot 2 \mathrm{H}_{2} \mathrm{O}$ was dissolved in $3 \mathrm{~mL} \mathrm{~N}_{2}$ degassed deionized water (solution A). $\mathrm{Na}_{3} \mathrm{PO}_{4} \cdot 12 \mathrm{H}_{2} \mathrm{O}$ and $\mathrm{Na}_{2} \mathrm{HPO}_{4}$ was dissolved in $3 \mathrm{~mL} \mathrm{~N}$ degassed deionized water (solution $\mathrm{B}$ ), in which the total molar amounts of $\mathrm{Na}_{3} \mathrm{PO}_{4} \cdot 12 \mathrm{H}_{2} \mathrm{O}$ and $\mathrm{Na}_{2} \mathrm{HPO}_{4}$ were kept at together $1.0 \mathrm{mmol}$, while the molar ratio was varied to adjust the $\mathrm{pH}$ of the solution. The actual molar ratio of $\mathrm{Na}_{3} \mathrm{PO}_{4} / \mathrm{NaH}_{2} \mathrm{PO}_{4}$, the $\mathrm{pH}$ of solution $\mathrm{B}$ and the $\mathrm{Ca} / \mathrm{P}$ atomic ratio of the obtained $\mathrm{AC}(\mathrm{H}) \mathrm{Ps}$ are summarized in the SI, Table $\mathrm{S} 1$. Under vigorous magnetic stirring and $\mathrm{N}_{2}$ protection, solution $\mathrm{B}$ was quickly added into solution A. Immediately, white precipitates of $\mathrm{AC}(\mathrm{H}) \mathrm{P}$ were formed, and $40 \mathrm{~mL}$ methanol was added to quench the reaction. Then the obtained mixture was transferred into 2 centrifuge tubes $(50 \mathrm{~mL})$ with $20 \mathrm{~mL}$ methanol, centrifuged at $9000 \mathrm{rpm}$ for $0.5 \mathrm{~min}$, washed with methanol 3 times, and once with acetone. The white powder obtained was dried by blowing $\mathrm{N}_{2}$ into the tubes at ambient temperature. Basic ACP was prepared at ambient temperature.

The reference samples HAP, DCPD, DCP, alpha-TCP and beta-TCP were purchased from SigmaAldrich; OCP was synthesized following a previously reported procedure. ${ }^{47}$ 
The chemical compositions and structure of the $\mathrm{AC}(\mathrm{H}) \mathrm{Ps}$ were determined by Inductively Coupled Plasma Optical Emission Spectrometry (ICP-OES), Thermogravimetric Analyses (TGA), Transmission Electron Microscopy (TEM), The X-ray powder Diffraction (XRD), Fourier Transform Infrared Spectroscopy (FTIR), Nuclear Magnetic Reonance (NMR), Synchrotron radiation, etc., and the corresponding experimental details are present in the SI.

\section{Simulation of the CHPC Structure}

Initial clusters were chosen to maintain the $\mathrm{Ca}: \mathrm{P}$ ratio of $1: 1$ with 6 calcium atoms. Thus for $\mathrm{Ca}_{6}\left(\mathrm{H}_{2} \mathrm{PO}_{4}\right)_{\mathrm{a}}\left(\mathrm{HPO}_{4}\right)_{\mathrm{b}}\left(\mathrm{PO}_{4}\right)_{\mathrm{c}} \mathrm{a}+\mathrm{b}+\mathrm{c}=6$ and $0 \leq \mathrm{a}, \mathrm{b}, \mathrm{c} \leq 6$. Additionally, it is unlikely that $\mathrm{H}_{2} \mathrm{PO}_{4}{ }^{-1}$ and $\mathrm{PO}_{4}{ }^{-}$

${ }^{3}$ would exist in the same cluster due to the favorability of a hydrogen transferring from $\mathrm{H}_{2} \mathrm{PO}_{4}{ }^{-1}$ to the more negative $\mathrm{PO}_{4}{ }^{-3}$. Thus, for clusters where $\mathrm{a} \geq \mathrm{b}$ then $\mathrm{c}$ was required to $\mathrm{be} \leq \mathrm{b}$ and vice versa, such that for $\mathrm{c} \geq \mathrm{b}$ then $\mathrm{a} \leq \mathrm{b}$. Clusters with an overall charge greater than or equal to \pm 2 were not examined. These constraints limit the composition of the system to 11 possible clusters (Table S3). For each cluster, an MD simulation was performed in the NVT ensemble in vacuum in a $50 \AA$ box for $5 \mathrm{~ns}$ at $3,000 \mathrm{~K}$ with angular momentum removed. The trajectory was reordered by potential energy and 10 configurations were chosen with differing potential energies. These configurations were then added to a pre-equilibrated $50 \AA$ water box and MD simulations at $300 \mathrm{~K}$ were performed. All molecular dynamics simulations employed the recent force field parameters of Demichelis et $\mathrm{al}^{48}$ and were performed using the LAMMPS code using a time step of 1 fs.

For consistency, new configurations for Posner's cluster $\left(\mathrm{Ca}_{9}\left(\mathrm{PO}_{4}\right)_{6}\right)$ were also considered, using a starting configuration with S6 symmetry described by Treboux. ${ }^{42}$ Simulations of the hydrated and nonhydrated cluster at $300 \mathrm{~K}$ were performed and retained essentially the same configuration (Figure S14). Even at high energy $(3,000 \mathrm{~K})$ there were no configurations with significantly different potential energies from the starting configuration (an example frame is shown in Figure S14). Thus, only one configuration was added to a pre-equilibrated $50 \AA$ water box and an MD simulation at $300 \mathrm{~K}$ was performed for $20 \mathrm{~ns}$, using the same parameters as for the other clusters. 
To explore the structure of CHPC in vacuum we also performed MD simulations of the hydrated and nonhydrated CHPC $\left[\mathrm{Ca}_{6}\left(\mathrm{HPO}_{4}\right)_{6}\left(\mathrm{H}_{2} \mathrm{O}\right)_{6}\right.$ and $\left.\mathrm{Ca}_{6}\left(\mathrm{HPO}_{4}\right)_{6}\right]$ in vacuum at $300 \mathrm{~K}$. These simulations were also performed in the NVT ensemble in a $50 \AA$ by $50 \AA$ by $50 \AA$ box for 5 ns using the LAMMPS code again with a time step of 1 fs.

To further confirm that the $\mathrm{Ca}_{6}\left(\mathrm{HPO}_{4}\right)_{6}$ cluster represents a viable structure, an ab initio molecular dynamics (AIMD) simulation was performed on this species in a cubic box of length $17.688 \AA$ containing 170 water molecules (552 atoms). The initial configuration was obtained by equilibration using the same force field model as above. AIMD used the Gaussian-augmented plane-wave approach, ${ }^{49}$ as embodied in the Quickstep module of the CP2K code. ${ }^{50}$ Here a TZ2P basis set was used for the valence orbitals of all elements except $\mathrm{Ca}$, where a DZVP basis was chosen, along with Goedecker-Teter-Hutter pseudopotentials $^{51}$ to represent the effective potential due to the core electrons and nucleus. A cut-off of 400 Ry was used for the auxiliary basis set for the electron density. The exchange-correlation was chosen to be BLYP with D3 dispersion corrections ${ }^{52}$ using the Becke-Johnson screening function at short-range. ${ }^{53}$ The dynamics used a time step of $0.5 \mathrm{fs}$ and an elevated temperature of $330 \mathrm{~K}$, since these conditions have been previously shown to correct for the over-structuring of water within GGA-based density functional theory. AIMD was run for $>50 \mathrm{ps}$ and the structure analyzed. Although this timescale is necessarily short with respect to water exchange rates in such systems, no significant change occurred in the cluster structure or hydrolysis state of any of the $\mathrm{HPO}_{4}{ }^{2-}$ ions, confirming that the cluster model is at least a local minimum on the DFT energy landscape.

\section{Simulation of Amorphous Models}

To create models for the amorphous material, 27 of the hydrated clusters $\mathrm{Ca}_{6}\left(\mathrm{HPO}_{4}\right)_{6}\left(\mathrm{H}_{2} \mathrm{O}\right)_{6}$ or $\mathrm{Ca}_{9}\left(\mathrm{PO}_{4}\right)_{6}\left(\mathrm{H}_{2} \mathrm{O}\right)_{12}$, were arranged on a grid. These cluster geometries were selected from the last frame of the aqueous NVT simulation described in the previous section. A 10 ns NPT run was used to equilibrate the system, which was then followed by 100 ns of NVT molecular dynamics. To verify that the models were not an artifact of all the clusters being initially oriented in the same way, the model was replicated 8 times with alternative orientations. The 27 clusters were both randomly oriented and placed in a cubic 
box of length $27 \AA$ for $\mathrm{Ca}_{6}\left(\mathrm{HPO}_{4}\right)_{6}\left(\mathrm{H}_{2} \mathrm{O}\right)_{6}$ and $40 \AA$ for $\mathrm{Ca}_{9}\left(\mathrm{PO}_{4}\right)_{6}\left(\mathrm{H}_{2} \mathrm{O}\right)_{12}$. For basic ACP NPT runs ranging from 2-7 ns were sufficient to equilibrate the system. However, for ACHP pockets of vacuum were observed to persist. Thus, a manual shrink was used to ensure that the density was at least $2 \mathrm{~g} / \mathrm{cm}^{3}$ for $\mathrm{Ca}_{6}\left(\mathrm{HPO}_{4}\right)_{6}\left(\mathrm{H}_{2} \mathrm{O}\right)_{6}$. This box was energy minimized, relaxed and then run with molecular dynamics using an NPT ensemble for $>3$ ns. After the cell parameters had equilibrated, NVT molecular dynamics was run for $\sim 30 \mathrm{~ns}$ for each amorphous model. The average of these NVT simulations was used to calculate the radial distribution functions. Specific simulation times are reported in Table S4. To compare the cluster structure within ACHP and basic ACP the trajectories of the 27 initial clusters were cut from the amorphous solids and superimposed using the central $\mathrm{Ca}$ in Posner's cluster and an arbitrary $\mathrm{Ca}$ followed by the center of mass in CHPC as a point of reference. MDAnalysis ${ }^{54}$ was used with the fast QCP algorithm to calculate the root mean square distance between the initial cluster and the cluster within the amorphous solid ${ }^{55}$ and the rotation matrices that minimize the $\mathrm{RMSD}^{56}$ and $3 \mathrm{D}$ atomic density maps were calculated using these aligned trajectories (see Figure S18). It was necessary to superimpose via both a $\mathrm{Ca}$ as well as center of mass for CHPC to ensure that the cluster was not cut across the periodic boundary conditions as well as being centrally aligned.

In order to compute the solid-state NMR spectra for the above two possible types of amorphous structure, further calculations were performed based on Kohn-Sham density functional theory. Here plane-wave calculations were conducted using the CASTEP $\operatorname{code}^{57}$ with a kinetic energy cut-off of $800 \mathrm{eV}$ and ultrasoft pseudopotentials. The PBE exchange-correlation functional was used in conjunction with dispersion corrections from the work of Grimme et al. ${ }^{58}$ Given that both amorphous materials are wide gap insulators and that the smallest cell dimension was greater than $13 \AA$, the Brillouin zone was sampled only at the gamma point. Both amorphous structures were relaxed to constant pressure under orthorhombic cell constraints such that all forces were below $0.05 \mathrm{eV} / \AA$ and stresses below $0.25 \mathrm{GPa}$. Once optimized, the chemical shifts were computed using an approach based on the gauge-including projector augmented wave (GIPAW) approach of Pickard and Mauri. ${ }^{59,60}$ In order to provide reference data for the chemical shift, an ordered model for hydroxyapatite was optimized using the same settings, 
except for the use of a $4 \times 4 \times 4$ Monkhorst-Pack mesh for the sampling of reciprocal space due to the smaller unit cell dimensions. Experimental data for the ${ }^{1} \mathrm{H}$ and ${ }^{31} \mathrm{P}$ chemical shifts were then taken from the work of Cho et al. ${ }^{61}$

\section{Acknowledgements}

BQL acknowledges financial support by the CSC-DAAD postdoc program for a postdoctoral stay at the University of Konstanz. DG is a Research Fellow of the Zukunftskolleg of the University of Konstanz. DMC is supported by the NSERC CGS-Alexander Graham Bell scholarship. PZ acknowledges the NSERC Discovery Grant for funding. The APS Sector 20 facilities are supported by the US DOE-Basic Energy Sciences (Contract No. DE-AC02-06CH11357), the CLS and its funding partners, the University of Washington, and the APS. Use of the APS, an Office of Science User Facility operated for the US DOE Office of Science by Argonne National Laboratory, was supported by the US DOE under Contract No. DE-AC02-06CH11357. NAG, PR and JDG thank the Australian Research Council for funding, as well as the Pawsey Supercomputer Centre and NCI for resources. We thank Uli Haunz for help with the NMR measurements; Michael Steyer for ICP-OES measurements; Jennifer Knaus for TGA measurements; Eduard Wiedenbeck for XRD measurements.

Keywords: Amorphous materials $\bullet$ Structure elucidation $\bullet$ Biomineralization $\bullet$ Calcium (ortho)phosphates $\bullet$ Posner's clusters

\section{Notes and References}

1. Dorozhkin, S. V.; Epple, M., Biological and medical significance of calcium phosphates. Angew. Chem. Int. Ed. 2002, 41, 3130-3146.

2. Lowenstam, H. A.; Weiner, S., On Biomineralization. Oxford University Press: New York, 1989.

3. Habraken, W.; Habibovic, P.; Epple, M.; Bohner, M., Calcium phosphates in biomedical applications: materials for the future? Mater. Today 2016, 19, 69-87.

4. Cartwright, J. H. E.; Checa, A. G.; Gale, J. D.; Gebauer, D.; Sainz-Diaz, C. I., Calcium Carbonate Polyamorphism and Its Role in Biomineralization: How Many Amorphous Calcium Carbonates Are There? Angew. Chem. Int. Ed. 2012, 51, 11960-11970.

5. Addadi, L.; Raz, S.; Weiner, S., Taking advantage of disorder: Amorphous calcium carbonate and its roles in biomineralization. Adv. Mater. 2003, 15, 959-970. 
6. Gower, L. B., Biomimetic Model Systems for Investigating the Amorphous Precursor Pathway and Its Role in Biomineralization. Chem. Rev. 2008, 108, 4551-4627.

7. Glimcher, M. J.; Bonar, L. C.; Grynpas, M. D.; Landis, W. J.; Roufosse, A. H., Recent Studies of Bone-Mineral - Is the Amorphous Calcium-Phosphate Theory Valid. J. Cryst. Growth 1981, 53, 100-119. 8. Weiner, S.; Sagi, I.; Addadi, L., Choosing the crystallization path less traveled. Science 2005, 309, 1027-1028.

9. Crane, N. J.; Popescu, V.; Morris, M. D.; Steenhuis, P.; Ignelzi, M. A., Raman spectroscopic evidence for octacalcium phosphate and other transient mineral species deposited during intramembranous mineralization. Bone 2006, 39, 434-442.

10. Suvorova, E. I.; Petrenko, P. P.; Buffat, P. A., Scanning and transmission electron microscopy for evaluation of order/disorder in bone structure. Scanning 2007, 29, 162-170.

11. Rey, C.; Combes, C.; Drouet, C.; Glimcher, M. J., Bone mineral: update on chemical composition and structure. Osteoporos. Int. 2009, 20, 1013-1021.

12. Nudelman, F.; Pieterse, K.; George, A.; Bomans, P. H. H.; Friedrich, H.; Brylka, L. J.; Hilbers, P. A. J.; de With, G.; Sommerdijk, N. A. J. M., The role of collagen in bone apatite formation in the presence of hydroxyapatite nucleation inhibitors. Nat. Mater. 2010, 9, 1004-1009.

13. Nitiputri, K.; Ramasse, Q. M.; Autefage, H.; McGilvery, C. M.; Boonrungsiman, S.; Evans, N. D.; Stevens, M. M.; Porter, A. E., Nanoanalytical Electron Microscopy Reveals a Sequential Mineralization Process Involving Carbonate-Containing Amorphous Precursors. Acs Nano 2016, 10, 6826-6835.

14. Yamashita, K.; Horisaka, Y.; Satomura, K.; Takagi, T., Analysis of minerals on initial calcification induced by bone matrix gelatin. Jpn. J. Oral Biol. 1991, 33, 166.

15. Gordon, L. M.; Cohen, M. J.; MacRenaris, K. W.; Pasteris, J. D.; Seda, T., Amorphous intergranular phases control the properties of rodent tooth enamel. Science 2015, 347, 746-750.

16. Tertuliano, O. A.; Greer, J. R., The nanocomposite nature of bone drives its strength and damage resistance. Nat. Mater. 2016, 15, 1195-1202.

17. Zhao, J.; Liu, Y.; Sun, W. B.; Yang, X. B., First detection, characterization, and application of amorphous calcium phosphate in dentistry. J. Dent. Sci. 2012, 7, 316-323.

18. Mahamid, J.; Aichmayer, B.; Shimoni, E.; Ziblat, R.; Li, C. H.; Siegel, S.; Paris, O.; Fratzl, P.; Weiner, S.; Addadi, L., Mapping amorphous calcium phosphate transformation into crystalline mineral from the cell to the bone in zebrafish fin rays. Proc. Natl. Acad. Sci. U. S. A. 2010, 107, 6316-6321.

19. Lowenstam, H. A.; Weiner, S., Transformation of Amorphous Calcium-Phosphate to Crystalline Dahllite in the Radular Teeth of Chitons. Science 1985, 227, 51-53.

20. Olszta, M. J.; Cheng, X. G.; Jee, S. S.; Kumar, R.; Kim, Y. Y.; Kaufman, M. J.; Douglas, E. P.; Gower, L. B., Bone structure and formation: A new perspective. Mater. Sci. Eng. R Rep. 2007, 58, 77-116.

21. Akiva, A.; Kerschnitzki, M.; Pinkas, I.; Wagermaie, W.; Yaniv, K.; Fratzl, P.; Addadi, L.; Weiner, S., Mineral Formation in the Larval Zebrafish Tail Bone Occurs via an Acidic Disordered Calcium Phosphate Phase. J. Am. Chem. Soc. 2016, 138, 14481-14487.

22. La Fontaine, A.; Zavgorodniy, A.; Liu, H.; Zheng, R.; Swain, M.; Cairney, J., Atomic-scale compositional mapping reveals Mg-rich amorphous calcium phosphate in human dental enamel. Sci. Adv. 2016, 2, e1601145.

23. Olszta, M. J.; Douglas, E. P.; Gower, L. B., Scanning Electron Microscopic Analysis of the Mineralization of Type I Collagen via a Polymer-Induced Liquid-Precursor (PILP) Process. Calcif. Tissue Int. 2003, 72, 583-591.

24. Bleek, K.; AndreasTaubert, New developments in polymer-controlled, bioinspired calcium phosphate mineralization from aqueous solution. Acta Biomater. 2013, 9, 6283-6321.

25. Jiao, K.; Niu, L. N.; Ma, C. F.; Huang, X. Q.; Pei, D. D.; Luo, T.; Huang, Q.; Chen, J. H.; Tay, F. R., Complementarity and Uncertainty in Intrafibrillar Mineralization of Collagen. Adv. Funct. Mater. 2016, 26, 6858-6875.

26. Dorozhkin, S. V., Amorphous calcium (ortho)phosphates. Acta Biomater. 2010, 6, 4457-4475.

27. Betts, F.; Posner, A. S., An X-ray radial distribution study of amorphous calcium phosphate. Mater. Res. Bull. 1974, 9, 353-360.

28. Posner, A. S.; Betts, F., Synthetic Amorphous Calcium-Phosphate and Its Relation to Bone-Mineral 
Structure. Acc. Chem. Res. 1975, 8, 273-281.

29. Holt, C.; Vankemenade, M. J. J. M.; Harries, J. E.; Nelson, L. S.; Bailey, R. T.; Hukins, D. W. L.; Hasnain, S. S.; Debruyn, P. L., Preparation of Amorphous Calcium-Magnesium Phosphates at Ph-7 and Characterization by X-Ray Absorption and Fourier-Transform Infrared-Spectroscopy. J. Cryst. Growth 1988, 92, 239-252.

30. Holt, C.; Vankemenade, M. J. J. M.; Nelson, L. S.; Sawyer, L.; Harries, J. E.; Bailey, R. T.; Hukins, D. W. L., Composition and Structure of Micellar Calcium-Phosphate. J. Dairy Res. 1989, 56, 411-416.

31. Zyman, Z.; Epple, M.; Goncharenko, A.; Rokhmistrov, D.; Prymak, O.; Loza, K., Thermally induced crystallization and phase evolution in powders derived from amorphous calcium phosphate precipitates with a Ca/P ratio of 1:1. J. Cryst. Growth 2016, 450, 190-196.

32. Zyman, Z.; Goncharenko, A.; Rokhmistrov, D., Kinetics and mechanisms of the transformation of precipitated amorphous calcium phosphate with a $\mathrm{Ca} / \mathrm{P}$ ratio of $1: 1$ to calcium pyrophosphates. $J$. Cryst. Growth 2017, 478, 117-122.

33. Layrolle, P.; Lebugle, A., Characterization and Reactivity of Nanosized Calcium Phosphates Prepared in Anhydrous Ethanol. Chem. Mater. 1994, 6, 1996-2004.

34. Holt, C.; Vankemenade, M. J. J. M.; Nelson, L. S.; Hukins, D. W. L.; Bailey, R. T.; Harries, J. E.; Hasnain, S. S.; Debruyn, P. L., Amorphous Calcium Phosphates Prepared at Ph 6.5 and 6.0. Mater. Res. Bull. 1989, 24, 55-62.

35. Habraken, W. J. E. M.; Tao, J. H.; Brylka, L. J.; Friedrich, H.; Bertinetti, L.; Schenk, A. S.; Verch, A.; Dmitrovic, V.; Bomans, P. H. H.; Frederik, P. M.; Laven, J.; van der Schoot, P.; Aichmayer, B.; de With, G.; DeYoreo, J. J.; Sommerdijk, N. A. J. M., Ion-association complexes unite classical and non-classical theories for the biomimetic nucleation of calcium phosphate. Nat. Comm. 2013, 4, Art. No. 1507.

36. Gebauer, D.; Kellermeier, M.; Gale, J. D.; Bergstrom, L.; Colfen, H., Pre-nucleation clusters as solute precursors in crystallisation. Chem. Soc. Rev. 2014, 43, 2348-2371.

37. Bailey, R. T.; Holt, C., Fourier transform infrared spectroscopy and characterisation of biological calcium phosphates. 1989; pp 93-120.

38. Eichert, D.; Salome, M.; Banu, M.; Susini, J.; Rey, C., Preliminary characterization of calcium chemical environment in apatitic and non-apatitic calcium phosphates of biological interest by X-ray absorption spectroscopy. Spectrochim. Acta, Part B 2005, 60, 850-858.

39. Shpak, A. P.; Karbovskii, V. L.; Trachevskii, V. V., Peculiarities of the electronic structure of the ultra disperse calcium hydroxyapatite. J. Electron. Spectrosc. Relat. Phenom. 1998, 88, 973-976.

40. Nelson, L. S.; Holt, C.; Harries, J. E.; Hukins, D. W. L., Amorphous calcium phosphates of different composition give very similar EXAFS spectra. Physica B 1989, 158, 105-106.

41. Holt, C.; Hukins, D. W. L., Structural Analysis of the Environment of Calcium Ions in Crystalline and Amorphous Calcium Phosphates by X-Ray Absorption Spectroscopy and a Hypothesis Concerning the Biological Function of the Casein Micelle. Int. Dairy J. 1991, 1, 151-165.

42. Treboux, G.; Layrolle, P.; Kanzaki, N.; Onuma, K.; Ito, A., Existence of Posner's cluster in vacuum. J. Phys. Chem. A 2000, 104, 5111-5114.

43. Hughes, J. M.; Cameron, M.; Crowley, K. D., Structural Variations in Natural F, Oh, and Cl Apatites. Am. Mineral. 1989, 74, 870-876.

44. Catti, M.; Ferraris, G.; Filhol, A., Hydrogen bonding in the crystalline state. CaHPO4 (monetite),P $\backslash$ overline $\{1\}$ or P1? A novel neutron diffraction study. Acta Crystallogr. Sect. B 1977, 33, 1223-1229.

45. Gebauer, D.; Gunawidjaja, P. N.; Ko, J. Y. P.; Bacsik, Z.; Aziz, B.; Liu, L. J.; Hu, Y. F.; Bergstrom, L.; Tai, C. W.; Sham, T. K.; Eden, M.; Hedin, N., Proto-Calcite and Proto-Vaterite in Amorphous Calcium Carbonates. Angew. Chem. Int. Ed. 2010, 49, 8889-8891.

46. Farhadi-Khouzani, M.; Chevrier, D. M.; Zhang, P.; Hedin, N.; Gebauer, D., Water as the Key to ProtoAragonite Amorphous CaCO3. Angew. Chem. Int. Ed. 2016, 55, 8117-8120.

47. Legeros, R. Z., Preparation of Octacalcium Phosphate (Ocp) - a Direct Fast Method. Calcif. Tissue Int. 1985, 37, 194-197.

48. Demichelis, R.; Garcia, N. A.; Raiteri, P.; Innocenti Malini, R.; Freeman, C. L.; Harding, J. H.; Gale, J. D., Simulation of Calcium Phosphate Species in Aqueous Solution: Force Field Derivation. J. Phys. 
Chem. B 2018, 122, 1471-1483.

49. Lippert, G.; Hutter, J.; Parrinello, M., The Gaussian and augmented-plane-wave density functional method for ab initio molecular dynamics simulations. Theor. Chem. Acc. 1999, 103, 124-140.

50. VandeVondele, J.; Krack, M.; Mohamed, F.; Parrinello, M.; Chassaing, T.; Hutter, J., Quickstep: Fast and accurate density functional calculations using a mixed Gaussian and plane waves approach. Comput. Phys. Commun. 2005, 167, 103-128.

51. Goedecker, S.; Teter, M.; Hutter, J., Separable dual-space Gaussian pseudopotentials. Phys. Rev. $B$ 1996, 54, 1703-1710.

52. Grimme, S.; Antony, J.; Ehrlich, S.; Krieg, H., A consistent and accurate ab initio parametrization of density functional dispersion correction (DFT-D) for the 94 elements $\mathrm{H}-\mathrm{Pu}$. J. Chem. Phys. 2010, 132, 154104.

53. Chamorro, E.; De Proft, F.; Geerlings, P., Hardness and softness reactivity kernels within the spinpolarized density-functional theory. J. Chem. Phys. 2005, 123, 154104.

54. Michaud-Agrawal, N.; Denning, E. J.; Woolf, T. B.; Beckstein, O., Software News and Updates MDAnalysis: A Toolkit for the Analysis of Molecular Dynamics Simulations. J. Comput. Chem. 2011, 32, 2319-2327.

55. Theobald, D. L., Rapid calculation of RMSDs using a quaternion-based characteristic polynomial. Acta Crystallogr., Sect. A 2005, 61, 478-480.

56. Liu, P.; Agrafiotis, D. K.; Theobald, D. L., Fast Determination of the Optimal Rotational Matrix for Macromolecular Superpositions. J. Comput. Chem. 2010, 31, 1561-1563.

57. Clark Stewart, J.; Segall Matthew, D.; Pickard Chris, J.; Hasnip Phil, J.; Probert Matt, I. J.; Refson, K.; Payne Mike, C., First principles methods using CASTEP. Z. Für Krist. - Cryst. Mater. 2005, 220, 567. 58. Grimme, S., Semiempirical GGA - type density functional constructed with a long - range dispersion correction. J. Comput. Chem. 2006, 27, 1787-1799.

59. Pickard, C. J.; Mauri, F., All-electron magnetic response with pseudopotentials: NMR chemical shifts. Phys. Rev. B 2001, 63, 245101.

60. Yates, J. R.; Pickard, C. J.; Mauri, F., Calculation of NMR chemical shifts for extended systems using ultrasoft pseudopotentials. Phys. Rev. B 2007, 76, 024401.

61. Cho, G.; Wu, Y.; Ackerman, J. L., Detection of Hydroxyl Ions in Bone Mineral by Solid-State NMR Spectroscopy. Science 2003, 300, 1123-1127. 
FOR TABLE OF CONTENTS USE ONLY

On the Short-Range Structure of Amorphous Calcium Hydrogen Phosphate

Bing-Qiang Lu, Natalya A. Garcia, Daniel M. Chevrier, Peng Zhang, Paolo Raiteri, Julian D. Gale and Denis Gebauer

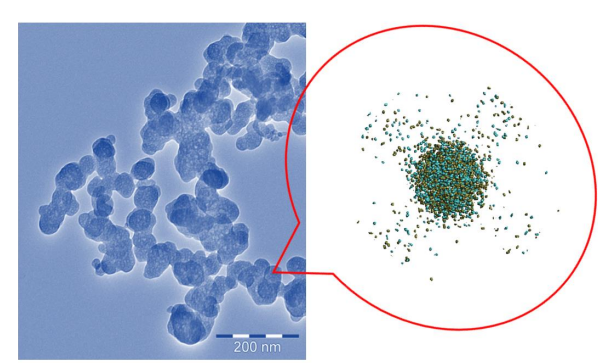

We propose a new model for the short-range structure of amorphous calcium hydrogen phosphate, which is distinct from Posner's cluster-based models. This is important for the determination of the structures of diverse ACPs with varying $\mathrm{Ca} / \mathrm{P}$ atomic ratios, and also for fundamental understanding of a major mineral class that is central to biomineralization in vertebrates. 